\title{
ANÁLISE DO DESEMPENHO DE CONCRETOS COM ADIÇĀO DE SÍLICA ATIVA SOB À AÇÃO DE CLORETO DE SÓDIO
}

\author{
CARVALHO, ANDRÉ \\ Mestrando em Engenharia de Materiais \\ Instituto Federal do Maranhão \\ Maranhão - Brasil \\ andre.luiz@acad.ifma.edu.br
}

\author{
REIS, LUCIANO \\ Doutorando em Engenharia Civil \\ Instituto Federal do Maranhão \\ Maranhão - Brasil \\ luciano.reis@ifma.edu.br
}

\section{RESUMO}

A atmosfera marinha é o ambiente natural de maior agressividade às estruturas de concreto devido à simultaneidade de processos físicos e químicos de deterioração. O estudo da adição de componentes ao concreto que melhorem sua durabilidade é uma linha de pesquisa promissora, a exemplo da sílica ativa. Entretanto, sua utilização ainda é uma incógnita, tal como o teor utilizado de modo a não comprometer as propriedades da estrutura e a influência do meio ambiente sob o concreto com adição de sílica. Posto isso, o presente estudo visa analisar o comportamento do concreto com substituição parcial de cimento por sílica ativa submetido à ação de cloreto de sódio, por meio de ciclos de imersão e secagem. Para tanto, foram moldados corpos de prova cilíndricos e prismáticos (com barras de aço) com e sem sílica ativa, utilizando teores de 4\%,8\% e 10\%, com relações água/aglomerante de 0.40 e 0.50 . Foram analisadas a resistência à compressão axial e o índice de vazios nos exemplares cilíndricos e avaliado o potencial de corrosão das armaduras das amostras prismáticas conforme a ASTM C876-09. Os resultados mostram que o teor de 4\% de sílica ativa não promove melhora do desempenho do concreto quando submetido à ação de solução de cloreto de sódio, fato este somente observado nos teores de substituição de 8 e $10 \%$.

Palavras-chave: sílica ativa, cloreto de sódio, resistência à compressão, potencial de corrosão, vazios.

\begin{abstract}
The marine atmosphere is the most aggressive natural environment to concrete structures due to the complex deterioration processes. Use of alternative materials in concrete that improve its durability is a promising line of research, such as silica fume. However, use of this residue is not totally understand, for instance, the content added in order not to compromise the mechanical properties and the influence of environment on blended concrete. Therefore, the aim of this paper is examine the behavior of concrete with silica fume subject to alternate wetting and drying cycles in sodium chloride solution. For this purpose, cylindrical and prismatic (with rebars) specimens with and without silica fume, using $4 \%, 8 \%$ and $10 \%$ contents, were made with water/binder ratios of 0,40 and 0,50 . The compressive strength and voids tests were carried out in the cylindrical specimens and the corrosion potential of the prismatic specimens was evaluated according to ASTM C876-09. The results show that the silica fume content of $4 \%$ does not improve concrete performance when subjected to sodium chloride solution action, behavior only observed in the contents of 8 and $10 \%$. Keywords: silica fume, sodium chloride, compressive strength, corrosion potentials, voids.
\end{abstract}

\section{INTRODUÇÃO}

O desempenho das estruturas de concreto compreende não somente a resistência mecânica, mas também a trabalhabilidade, o acabamento, a estética, a integridade e, principalmente, a durabilidade (TUTIKIAN et al., 2011). A durabilidade é definida como a capacidade que a estrutura possui em resistir às influências ambientais previstas, ou seja, resistir às ações físicas e químicas que agem sobre as estruturas, independentemente daquelas previstas no dimensionamento (ABNT, 2014).

As estruturas inseridas em ambientes marinhos estão expostas a diversos mecanismos químicos e físicos de deterioração, tornando-os meios de alta complexidade para os estudos de durabilidade. A degradação em uma estrutura exposta ao ambiente marinho geralmente não ocorre de forma uniforme, dado que os mecanismos de ataque variam 
conforme o nível da maré. Mesmo aquelas que não estão em contato direto com o meio marinho estão sujeitas à sua agressividade (MEHTA e MONTEIRO, 2008).

Para as estruturas de concreto em ambientes que contém cloreto, a prematura corrosão das armaduras devido a esse ânion é um grande desafio no que tange sua durabilidade e desempenho (GJØRV, 2015). O ataque químico da água marinha decorre do alto número de sais dissolvidos, cerca de $35 \mathrm{~g} / \mathrm{l}$, sendo as principais concentrações iônicas de $\mathrm{Na}^{+} \mathrm{e}$ $\mathrm{Cl}^{-}$(MEHTA e MONTEIRO, 2008). A penetração dos íons cloreto no concreto, ao alcançar a armadura na presença de água e oxigênio, causa a destruição da película passivadora, iniciando o processo corrosivo, cujos produtos tendem a ocupar volumes superiores em relação ao aço original, gerando fissuras e, posteriormente, delaminação. Ademais, ocorre a redução da área de seção transversal, que reduz a capacidade de carga da estrutura (NEVILLE, 2016).

A zona situada entre as marés alta e baixa, denominada de variação de marés, é a região mais crítica de ataques, visto que está submetida aos ciclos de molhagem e secagem, possibilitando a cristalização de sais nos poros e corrosão das armaduras, além da presença de processos erosivos devido ao impacto das ondas e/ou partículas sólidas (MEHTA e MONTEIRO, 2008).

Adições são materiais utilizados em conjunto com cimento, que aprimoram as propriedades do concreto através de atividade hidráulica e/ou pozolânica; um material hidráulico reage quimicamente com água para formar compostos cimentícios, enquanto as pozolanas, materiais silicosos ou silicoaluminosos finamente divididos, reagem quimicamente com o hidróxido de cálcio na presença de umidade para formar compostos com propriedades aglomerantes (KOSMATKA et al., 2011). A sílica presente nos materiais pozolânicos deve ser amorfa, pois a estrutura cristalina apresenta baixa reatividade e, desse modo, pozolanas naturais, metacaulim, cinzas de casca de arroz, cinzas volantes e sílica ativa correspondem a essa categoria (NEVILLE, 2016).

A sílica ativa é um resíduo da produção do silício e de ligas de ferrosilício, por meio do aquecimento de quartzo (fonte de sílica), carvão e pedaços de madeira em fornos a arco elétrico para remoção do oxigênio da sílica. Neste processo, é produzido um gás denominado óxido de silício $(\mathrm{SiO})$, que ao resfriar, condesa-se, formando dióxido de silício $\left(\mathrm{SiO}_{2}\right)$ em estado amorfo, coletado em filtros para remoção de impurezas (KOSMATKA, et al., 2011).

Os efeitos benéficos da sílica no concreto não se limitam à sua atividade pozolânica. É observada ainda uma interação física, através do depósito das partículas extremamente finas sobre os agregados, ou seja, na interface agregado-matriz cimentícia, reduzindo a porosidade do sistema, conhecido como efeito microfíler (NEVILLE, 2016).

A sílica ativa é normalmente utilizada em teores que variam entre 5 e $10 \%$ da massa do material cimentício para produção de concretos de alta resistência, conforme descrito por Kosmatka et al. (2011) e Neville (2016) ou entre 4 e 15\% de acordo com a Silica Fume Association (2005). Embora a sílica ativa seja normalmente incorporada à mistura no dosador, em alguns países são comercializados cimentos com teores que variam de 6,5 a 8\% NEVILLE (2016).

A adição de sílica ativa ao concreto objetiva não somente a produção de concretos de alta resistência, mas também melhorar seu desempenho por meio da baixa permeabilidade do conjunto, pois o ingresso de substâncias químicas agressivas ao concreto e danos a armadura é postergado (NEVILLE, 2016).

\section{PROGRAMA EXPERIMENTAL}

\subsection{Caracterização do material}

\subsubsection{Aglomerante}

O cimento exigido para a pesquisa não deveria possuir outras adições em sua composição, devido a possibilidade de interferência no processo de hidratação em função da adição da sílica ativa. Atendendo a este requisito, foi selecionado o cimento tipo CP I 40 (cimento Portland comum), cuja massa específica determinada através do método de ensaio descrito pela NBR 16605:2017 é de 3,06 g/ $\mathrm{cm}^{3}$. De acordo com Kosmatka et al. (2011), a massa específica do cimento pode variar entre 2,90 e $3,15 \mathrm{~g} / \mathrm{cm}^{3}$ e, portanto, o valor encontrado se apresenta dentro do intervalo. 


\subsubsection{Agregados}

Os agregados utilizados na presente pesquisa incluem areia natural e pedra britada, adquiridos no comércio local. A distribuição do tamanho das partículas foi realizada conforme as diretrizes da NBR NM 248:2003, enquanto as massas específicas da areia e da brita foram determinadas conforme as NBRs NM 52:2009 e NM 53:2009, respectivamente. Foi determinada ainda a massa unitária no estado compactado da areia, segundo a NBR NM 45:2006. Os resultados da caracterização são apresentados na Tabela 1.

Tabela 1 - Resultados de ensaios de caracterização dos agregados

\begin{tabular}{c|c|c}
\hline Ensaio & Areia & Brita \\
\hline Módulo de finura & 1,40 & - \\
\hline Massa específica $\left(\mathrm{g} / \mathrm{cm}^{3}\right)$ & 2,66 & 2,81 \\
\hline $\begin{array}{c}\text { Dimensão máxima } \\
\text { característica }(\mathrm{mm})\end{array}$ & 19,00 & - \\
\hline $\begin{array}{c}\text { Massa unitária no estado } \\
\text { compactado }\left(\mathrm{kg} / \mathrm{m}^{3}\right)\end{array}$ & - & 1650,00 \\
\hline
\end{tabular}

O módulo de finura do agregado miúdo mostra que areia possui uma granulometria muito fina, fora da zona utilizável inferior conforme a NBR 7211:2009, característico das areias da região de São Luís. Com relação à dimensão máxima característica do agregado graúdo, pode-se dizer que o material utilizado trata-se da pedra britada comercialmente denominada tipo 1. A massa específica de ambos os materiais se apresentam dentro dos valores esperados que, para areia, varia entre 2,60 e 2,90 g/ $\mathrm{cm}^{3}$ e, para brita de origem basáltica, entre 2,60 e 3,00 g/ $\mathrm{cm}^{3}$, conforme Neville (2016), assim como a massa unitária do agregado gráudo.

\subsubsection{Sílica ativa}

A sílica ativa não densificada foi doada pela empresa de concretagem Supermix, localizada em São Luís. As características físicas e químicas fornecidas pelo fabricante são apresentadas na Tabela 2.

Tabela 2 - Caracterização física e química da sílica ativa

\begin{tabular}{|c|c|c|c|}
\hline \multicolumn{2}{|c|}{ Parâmetros físicos } & \multicolumn{2}{|l|}{ Parâmetros químicos } \\
\hline \multirow{2}{*}{ Densidade $\left(\mathrm{g} / \mathrm{cm}^{3}\right)$} & \multirow{2}{*}{2,22} & Equivalente alcalino, em $\mathrm{Na}_{2} \mathrm{O}(\%)$ & 0,7 \\
\hline & & Perda ao fogo (\%) & 3,7 \\
\hline \multirow{2}{*}{$\mathrm{pH}$} & \multirow{2}{*}{7,9} & $\mathrm{SiO}_{2}(\%)$ & 93,0 \\
\hline & & $\mathrm{Na}_{2} \mathrm{O}(\%)$ & 0,2 \\
\hline \multirow{2}{*}{ Umidade $(\%)$} & \multirow{2}{*}{0,1} & $\mathrm{Fe}_{2} \mathrm{O}_{3}(\%)$ & 0,5 \\
\hline & & $\mathrm{CaO}(\%)$ & 0,5 \\
\hline \multirow{3}{*}{ Retido 45mm (\#325) (\%) } & \multirow{3}{*}{3,7} & $\mathrm{MgO}(\%)$ & 0,4 \\
\hline & & $\mathrm{Al}_{2} \mathrm{O}_{3}(\%)$ & 0,2 \\
\hline & & $\mathrm{K}_{2} \mathrm{O}(\%)$ & 0,9 \\
\hline
\end{tabular}

\subsubsection{Aditivo plastificante}

O aditivo polifuncional redutor de água Polykem ${ }^{\mathrm{TM}} 805$ foi utilizado para melhorar a trabalhabilidade do concreto no estado fresco. O seu uso se fez necessário nas misturas com adição de sílica ativa com a menor relação água/aglomerante, visto que o consumo de água aumenta devido a finura das partículas.

\subsubsection{Barras de aço}

As barras de aço utilizadas para o ensaio de potencial de corrosão foram do tipo CA 50, com $10 \mathrm{~mm}$ de diâmetro e 10 $\mathrm{cm}$ de comprimento. Para fins de padronização, a armadura foi submetida ao processo de limpeza química e mecânica especificado pela ASTM G1:2011. Inicialmente, as barras foram imersas em solução de ácido clorídrico e água destilada em proporção de 1:1, acrescido de 3,5 g/l de hexametilenotetramina, durante 10 minutos. Em seguida, realizou-se a lavagem individual em água corrente com escova de cerdas plásticas e, por fim, secagem dos espécimes com papel toalha, que foram mantidos em estufa até o momento da moldagem. A Figura 1 mostra as etapas de imersão e lavagem das barras de aço, enquanto na Figura 2 é possível comparar uma amostra nos estados inicial e final. 


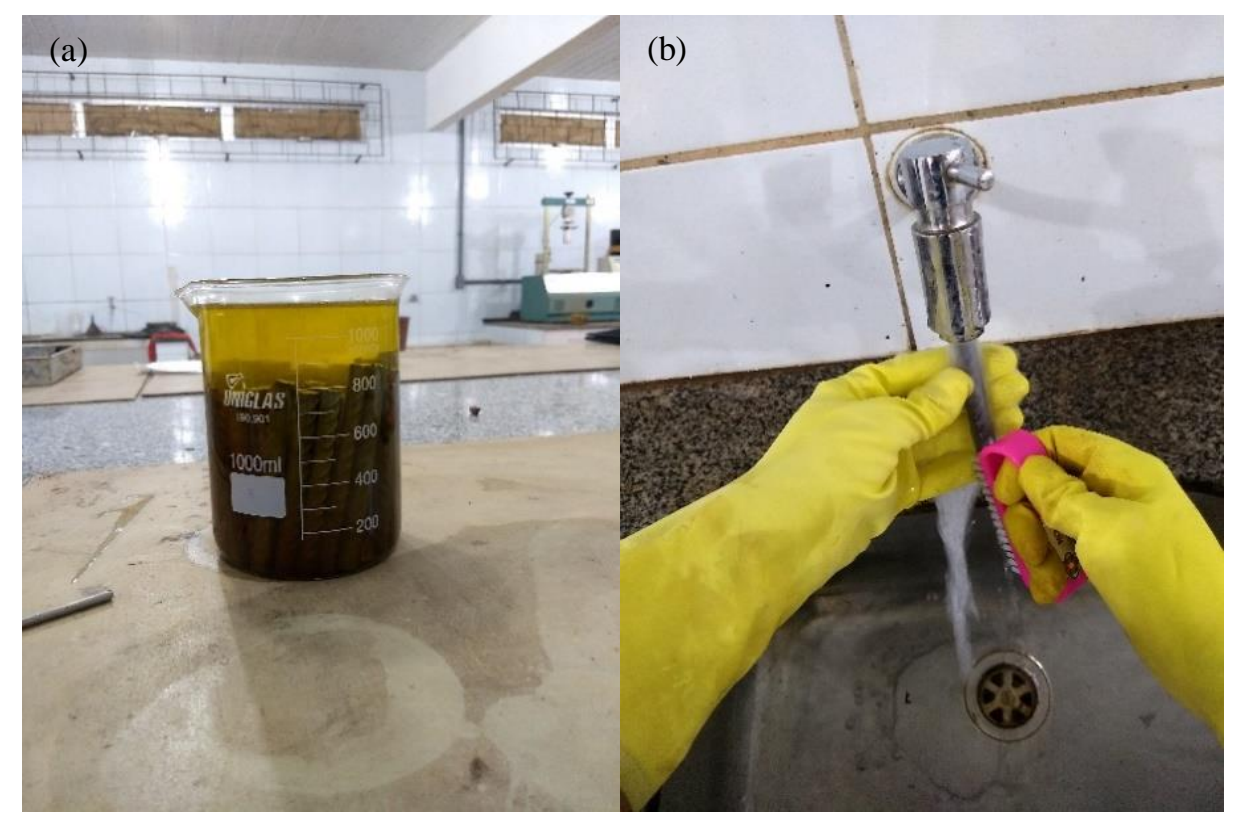

Figura 1: Limpeza das barras (a) imersão em solução de $\mathrm{HCl}$, água destilada e $\mathrm{C}_{6} \mathrm{H}_{12} \mathrm{~N}_{4}$; (b) lavagem em água corrente

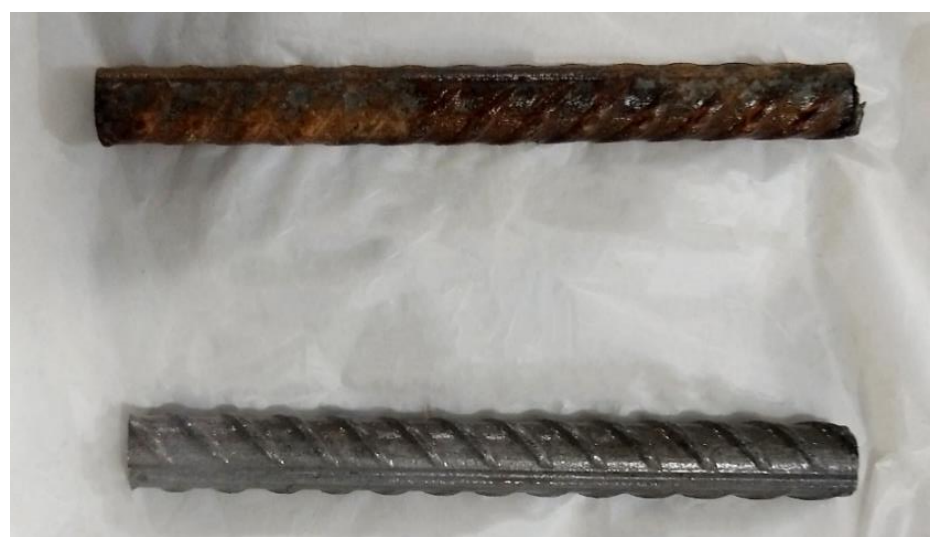

Figura 2: Comparação entre as barras antes (superior) e após (inferior) as etapas de limpeza química/mecânica

\subsection{Definição do programa experimental}

Com o intuito de melhor compreensão do programa experimental, detalhou-se na Tabela 3 as propriedades estudadas, quantidade de amostras, idades de ensaios e normas utilizadas.

Tabela 3 - Ensaios e métodos utilizados

\begin{tabular}{c|c|c|c}
\hline \multicolumn{2}{c|}{ Ensaio } & Amostragem & Método de ensaio \\
\hline $\begin{array}{c}\text { Caracterização } \\
\text { mecânica }\end{array}$ & $\begin{array}{c}\text { Resistência à } \\
\text { compressão }\end{array}$ & $\begin{array}{c}03 \text { amostras para cada idade } \\
\text { de cada grupo } \\
\text { Idades: 07, 28, 49 e 56 dias }\end{array}$ & NBR 5739:2007 \\
\hline $\begin{array}{c}\text { Caracterização } \\
\text { física }\end{array}$ & $\begin{array}{c}\text { Índice de } \\
\text { vazios }\end{array}$ & $\begin{array}{c}02 \text { amostras para cada grupo } \\
\text { Idade: 28 dias }\end{array}$ & NBR 9778:2005 \\
\hline $\begin{array}{c}\text { Caracterização } \\
\text { eletroquímica }\end{array}$ & $\begin{array}{c}\text { Potencial de } \\
\text { corrosão }\end{array}$ & $\begin{array}{c}02 \text { amostras para cada grupo } \\
\text { Idade: 56 dias }\end{array}$ & ASTM C876-09 \\
\hline
\end{tabular}

O programa experimental foi planejado com o próposito de verificar a influência no desempenho de concreto com substituição parcial de cimento por sílica ativa, em massa, frente à ação de cloreto de sódio. Três teores foram selecionados, $4 \%, 8 \%$ e 10\%. Além destes, corpos de prova contendo apenas cimento Portland foram moldados como referência para fins de comparação. Os teores escolhidos se encontram dentro do intervalo que apresenta resultados mais significativos em relação a ganhos de resistência e durabilidade, conforme Kosmatka et al. (2011), Neville (2016) e a Silica Fume Association (2005). 
Os fatores água/aglomerante foram definidos a partir das especificações NBR 6118:2014, que recomenda a utilização de fatores de, no máximo, 0,45 para concretos sob agressividade marinha, ambiente cuja concentração de cloreto de sódio é bastante elevada. Desse modo, estabeleceu-se dois fatores, 0,40 e 0,50. O primeiro é inferior ao máximo sugerido, o segundo, entretanto, é superior e sua escolha está pautada na tentativa do uso de um valor acima do recomendado, reduzindo o consumo de cimento para verificar sua potencial aplicação com sílica ativa sob ação do cloreto.

A dosagem para definição da proporção entre os materiais foi realizada através do método ABCP/ACI, uma vez que este é fundamentado nas propriedades físicas dos constituintes do concreto. Para cada relação a/ag foi determinado um traço inicial, apresentado na Tabela 4, no qual o cimento foi substituído por sílica nos teores anteriormente citados. Por exemplo, para um teor de $10 \%$ de sílica, a massa de aglomerante é formada por $0,90 \mathrm{~kg}$ de cimento e $0,10 \mathrm{~kg}$ de sílica.

Tabela 4 - Traço base obtido por meio da dosagem ABCP/ACI

\begin{tabular}{c|c}
\hline Relação água/aglomerante & Traço unitário (em massa) \\
\hline 0,40 & $1,00: 0,95: 2,44$ \\
\hline 0,50 & $1,00: 1,40: 3,05$ \\
\hline
\end{tabular}

Os corpos de prova cilíndricos possuem $10 \mathrm{~cm}$ de diâmetro e $20 \mathrm{~cm}$ de altura, enquanto os prismáticos possuem dimensões de $15 \times 15 \times 10 \mathrm{~cm}$, em que são dispostas quatro barras de aço, com cobrimentos de $25 \mathrm{~mm}, 30 \mathrm{~mm}, 40 \mathrm{~mm}$ e $50 \mathrm{~mm}$, com $2 \mathrm{~cm}$ expostos no topo. Após a moldagem, os espécimes foram submetidos à cura saturada por 28 dias.

Como citado anteriormente, o ataque da água do mar no concreto se apresenta de forma heterogênea, sendo a região mais crítica a zona de variação de marés. Desse modo, após 28 dias em cura saturada, os espécimes foram expostos a umidade ambiente por quatro dias e, em seguida, parcialmente imersos em solução de 5\% de cloreto de sódio por três dias, constituindo assim, um ciclo de sete dias. O tempo total de simulação foi de 28 dias, totalizando quatro ciclos. A metodologia e concentração de $\mathrm{NaCl}$ utilizadas foram baseadas em estudos anteriores (LIMA, 2017; SANTOS, 2016).

\subsection{Métodos de ensaio}

\subsubsection{Resistência à compressão axial}

O procedimento para determinação da resistência à compressão axial foi assistido pelas orientações da NBR 5739:2015 "Concreto - ensaios de compressão de corpos-de-prova cilíndricos". Os corpos de prova foram testados nas idades de 07 e 28 dias, enquanto aqueles submetidos à ação do cloreto de sódio foram rompidos nas idades de 49 e 56 dias. O ensaio foi realizado em tréplica e utilizado o procedimento de Chauvenet para descarte de valores questionáveis.

\subsection{2 Índice de vazios}

O processo utilizado para caracterização do índice de vazios dos corpos de prova foi o recomendado pela NBR 9778:2005 "Argamassa e concreto endurecidos - determinação da absorção de água, índice de vazios e massa específica". Após os 28 dias em cura saturada, são determinadas a massa seca após $72 \mathrm{~h}$ em secagem em estufa à temperatura de $100{ }^{\circ} \mathrm{C}, \mathrm{m}_{\mathrm{s}}$, e massas saturada e aparente imersa, $\mathrm{m}_{\text {sat }}$ e $\mathrm{m}_{\mathrm{i}}$, respectivamente, após $72 \mathrm{~h}$ em imersão em água. O índice de vazios admitido é a média de duas determinações, sendo cada uma destas calculada pela fórmula:

$$
\mathrm{V}(\%)=\frac{\mathrm{m}_{\mathrm{sat}}-\mathrm{m}_{\mathrm{g}}}{\mathrm{m}_{\mathrm{i}}}
$$

\subsubsection{Potencial de corrosão}

A metodologia escolhida para avaliação da deterioração das barras de aço foi o potencial de corrosão, seguindo as orientações da norma ASTM C876-09 "Standard test method for corrosion potentials of uncoated reinforcing steel in concrete". O equipamento descrito pela norma é constituído por uma meia célula de cobre/sulfato de cobre, dispositivo de junção elétrica, solução de contato elétrico, voltímetro e fios condutores elétricos.

O eletrodo de referência de cobre/sulfato de cobre confeccionado compreende um tubo PVC cujo interior dispõe de uma haste de cobre imersa em solução aquosa saturada de sulfato de cobre, com a extremidade inferior composta por um cap com pequenos furos para proporcionar a continuidade elétrica entre os eletrodos de referência e trabalho (barra de aço do concreto). A conexão dos eletrodos faz surgir um fluxo de elétrons da armadura em direção ao eletrodo de 
referência, que, ao passar pelo voltímetro, indica uma diferença de potencial. O valor obtido apenas é considerado válido caso se apresente em uma faixa de $\pm 0,02 \mathrm{~V}$ por, no mínimo, cinco minutos. Havendo variação, o concreto deve ser umedecido até que haja estabilização. O ensaio de potencial de corrosão foi realizado nos corpos de prova prismáticos, em duas amostras para a idade de 56 dias. Na Figura 3 são mostrados os equipamentos utilizados para o ensaio. A Tabela 5 apresenta a interpretação dos resultados conforme a ASTM C876-09.

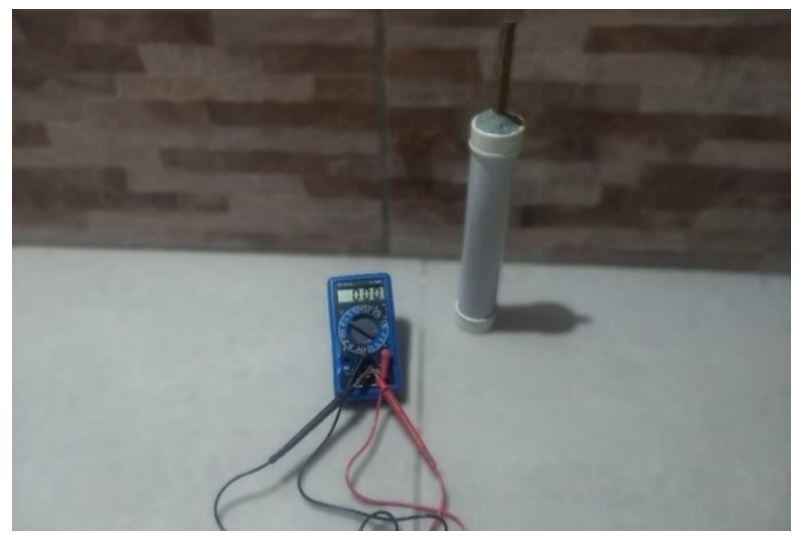

Figura 3: Eletrodo de referência e voltímetro utilizados para realização do ensaio de potencial de corrosão

Tabela 5 - Interpretação dos resultados do potencial de corrosão para eletrodo cobre/sulfato de cobre

\begin{tabular}{cc}
\hline Valor & Interpretação \\
\hline Mais positivo que $-0,20 \mathrm{~V}$ & Baixa probabilidade de corrosão $(\leq 10 \%)$ \\
\hline No intervalo de $-0,20$ a $-0,35 \mathrm{~V}$ & Corrosão incerta \\
\hline Mais negativo que $-0,35 \mathrm{~V}$ & Alta probabilidade de corrosão $(\geq 90 \%)$ \\
\hline
\end{tabular}

Fonte: Adaptado de American Society for Testing and Materials, 2011.

\section{RESULTADOS}

\subsection{Resistência à compressão simples}

A média dos resultados do ensaio de resistência à compressão axial simples são apresentadas nos gráficos das Figuras 4 e 5 para as relações água/aglomerante de 0,40 e 0,50 , respectivamente.

$0 \% \mathrm{SA} \quad 4 \% \mathrm{SA} \quad \square \% \mathrm{SA} \quad \square 10 \% \mathrm{SA}$

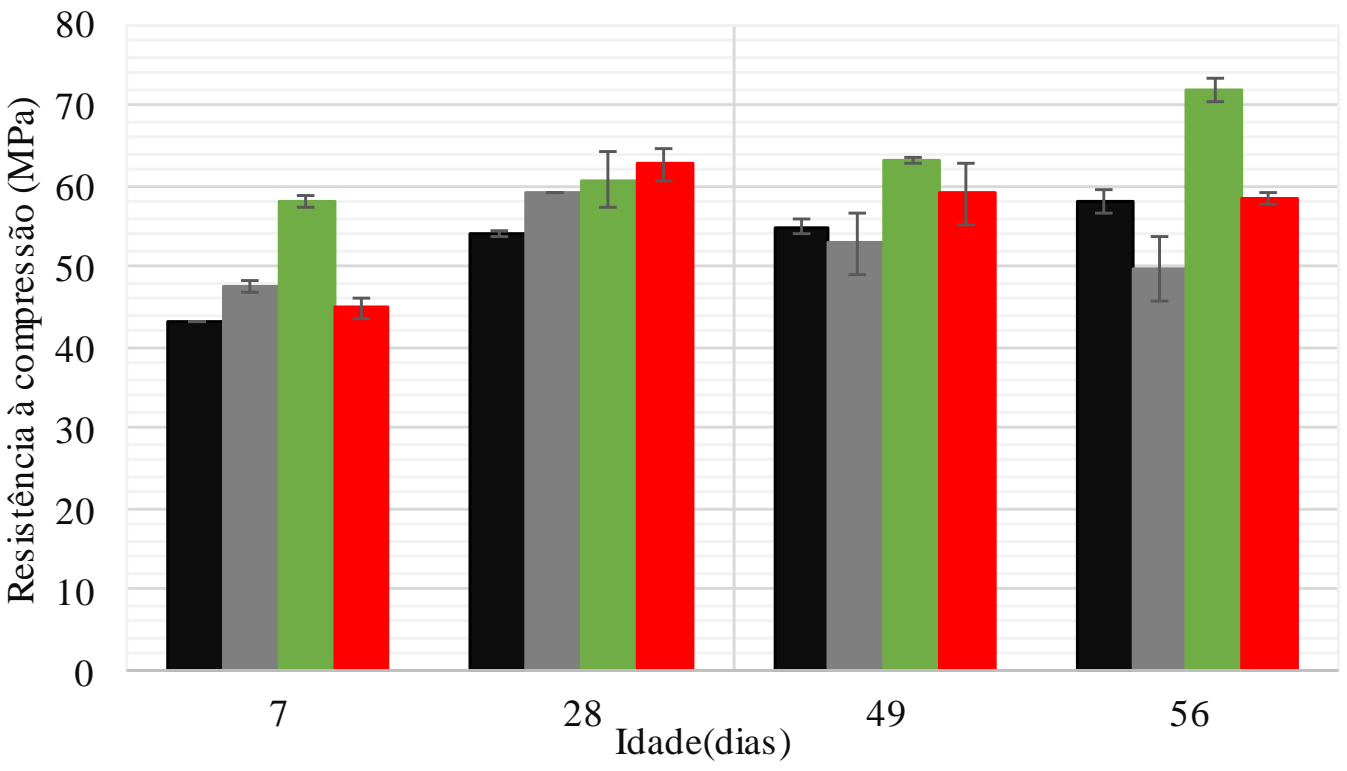

Figura 4: Resistência à compressão axial simples dos corpos de prova com relação a/ag 0,40 


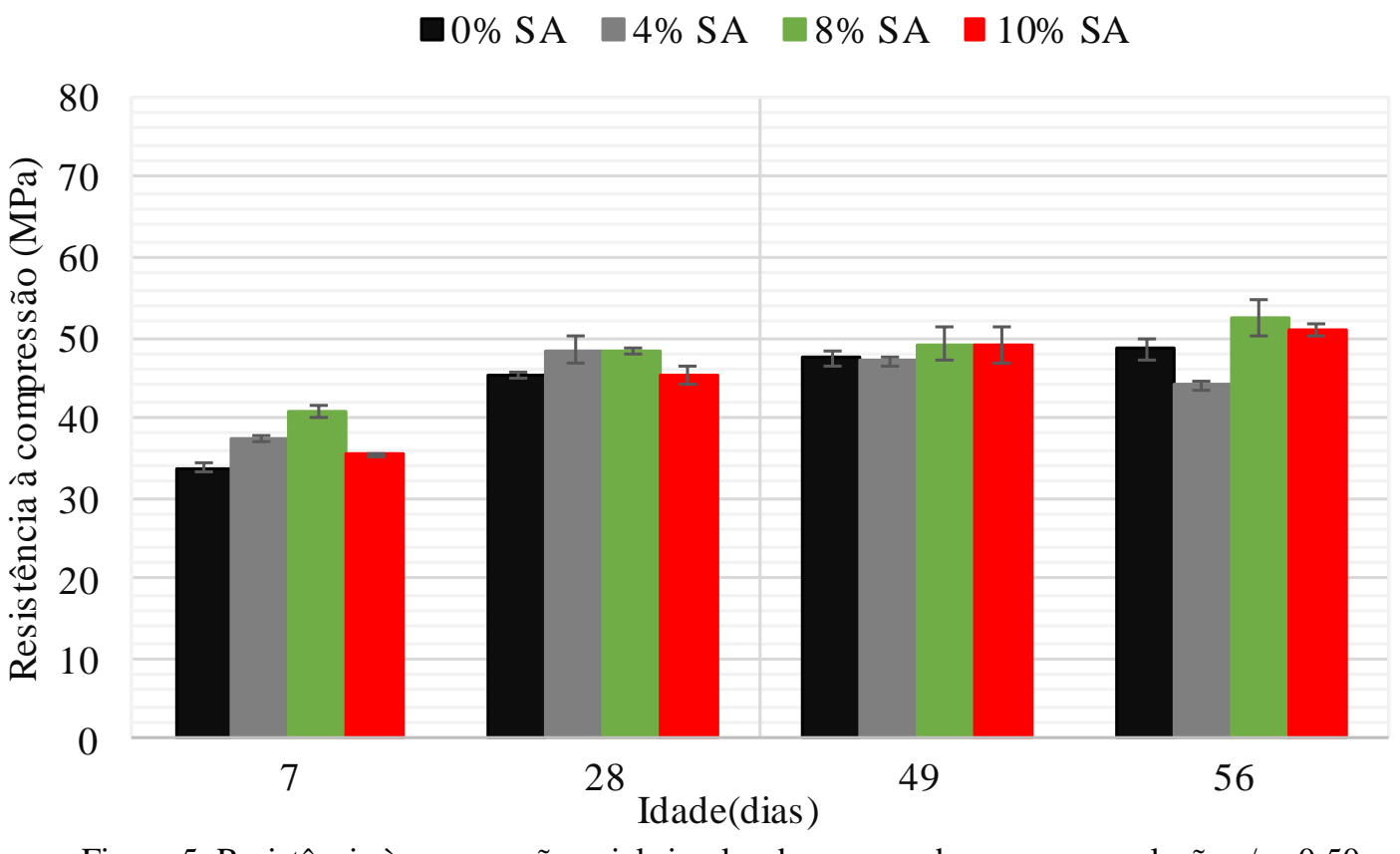

Figura 5: Resistência à compressão axial simples dos corpos de prova com relação a/ag 0,50

Os resultados do período em cura saturada, correspondentes às idades de 07 e 28 dias, mostram que o uso da sílica ativa, bem como a relação água/aglomerante, possuem grande influência na resistência à compressão. Nos grupos com relação a/ag 0,40, aos 07 dias, as maiores resistências foram observadas nas amostras com adição, fato também observado aos 28 dias, com os teores de 8 e 10\% apresentando os melhores resultados. O teor de $4 \%$ também apresentou resultados bastantes significativos em relação ao concreto referência.

Esse comportamento decorre da ação pozolânica da sílica ativa que ao reagir com o hidróxido de cálcio do cimento, importante para manutenção da alcalinidade do sistema, transforma-o em silicato de cálcio hidratado (C-S-H), principal composto responsável pela resistência do concreto (TUTIKIAN et al., 2011). Seu efeito é potencializado pela ação defloculadora do aditivo nas partículas de cimento, que permite um maior grau de hidratação.

Para a relação a/ag de 0,50 , ainda em relação ao período em cura saturada, os corpos de prova com sílica ativa apresentaram resistência à compressão superior em comparação ao concreto referência aos 07 dias. Contudo, aos 28 dias, as amostras com teor de $4 \%$ apresentaram melhores resultados em comparação aos demais, contrariamente ao previsto. A ausência do aditivo plastificante explica esse fato. Neville (2016) afirma que as propriedades mecânicas do concreto podem ser otimizadas por meio da redução da relação água/cimento; no entanto, esse fator possui um valor limite, para que as reações de hidratação ocorram de forma satisfatória. Assim, quanto maior a substituição de cimento por sílica acima de $4 \%$, menor a resistência alcançada aos 28 dias devido à indisponibilidade de água para as reações de hidratação em consequência da não utilização do aditivo redutor de água.

A segunda análise, referente ao período sob ação de cloreto de sódio, corresponde aos 49 e 56 dias. O concreto referência, em ambas relações água/aglomerante, apresentou ganho de resistência contínuo. Os corpos de prova com teor de $4 \%$, para as duas relações a/ag e idades, exibiram queda de resistência, fato esperado, dado que, segundo Sugamosto (2007), a redução da penetração de cloretos no concreto é reduzida para teores entre 5 e $12 \%$, e, consequentemente, efetivos em prevenir o ataque pela cristalização do sal. O teor de $8 \%$, para as relações a/ag de 0,40 e 0,50, apresentou ganho de resistência mesmo sob agressividade do meio, em ambas idades. O teor de $10 \%$, para a relação a/ag de 0,40 , apresentou uma pequena queda de resistência, praticamente insignificante sob uma perspectiva estatística, enquanto que para a relação a/ag de 0,50, o concreto apresentou ganho de resistência em ambas as idades. 


\section{2 Índice de vazios}

Os resultados do ensaio de determinação do índice de vazios médio dos corpos de prova cilíndricos para a idade de 28 dias são apresentados na Tabela 6.

Tabela 6 - Índice de vazios médio aos 28 dias

\begin{tabular}{l|c|c}
\hline \multirow{2}{*}{ Relação a/ag } & Teor de sílica ativa & Índice de vazios médio (\%) \\
\hline \multirow{4}{*}{0,40} & $0 \%$ & 10,20 \\
\cline { 2 - 3 } & $4 \%$ & 12,78 \\
\cline { 2 - 3 } & $8 \%$ & 9,31 \\
\cline { 2 - 3 } & $10 \%$ & 9,63 \\
\hline \multirow{4}{*}{0,50} & $0 \%$ & 11,62 \\
\cline { 2 - 3 } & $4 \%$ & 13,23 \\
\cline { 2 - 3 } & $8 \%$ & 11,36 \\
\cline { 2 - 3 } & $10 \%$ & 11,53 \\
\hline
\end{tabular}

Os resultados apresentados são semelhantes para as duas relações água/aglomerante. Para os teores de 8 e $10 \%$ de sílica, o índice de vazios reduz em relação ao concreto referência, como consequência das dimensões microscópicas de suas partículas, que preenchem os vazios não alcançados pelos demais componentes do concreto. Entretanto, o mesmo não é observado para o teor de $4 \%$, que ocorre porque uma quantidade de sílica inferior a 5\% sob a massa do material cimentício não é adequada para cobrir toda a superfície dos agregados graúdos (NEVILLE, 2016). Contudo, o aumento da resistência ainda é observado em função das reações pozolânicas. O aumento da quantidade de vazios explica ainda a queda de resistência nos corpos de prova submetidos à ação do cloreto de sódio nesses grupos.

\subsection{Potencial de corrosão}

Os resultados do ensaio de potencial de corrosão utilizando meia-célula de cobre/sulfato de cobre aos 56 dias são apresentados na Tabela 7 .

Tabela 7 - Resultados do ensaio de potencial de corrosão

\begin{tabular}{|c|c|c|c|c|c|}
\hline \multirow{2}{*}{$\begin{array}{c}\text { Teor de sílica ativa } \\
(\%)\end{array}$} & \multirow{2}{*}{ Cobrimento (mm) } & \multirow{2}{*}{\multicolumn{2}{|c|}{$\frac{\text { Relação a/ag } 0,40}{\text { Potencial }(-\mathrm{V})}$}} & \multirow{2}{*}{\multicolumn{2}{|c|}{$\begin{array}{c}\text { Relação a/ag 0,50 } \\
\text { Potencial (-V) }\end{array}$}} \\
\hline & & & & & \\
\hline \multirow{4}{*}{0} & 25 & 0,22 & 0,24 & 0,23 & 0,25 \\
\hline & 30 & 0,27 & 0,23 & 0,22 & 0,21 \\
\hline & 40 & 0,29 & 0,22 & 0,22 & 0,21 \\
\hline & 50 & 0,20 & 0,19 & 0,21 & 0,20 \\
\hline \multirow{4}{*}{4} & 25 & 0,21 & 0,22 & 0,33 & 0,35 \\
\hline & 30 & 0,25 & 0,23 & 0,23 & 0,25 \\
\hline & 40 & 0,23 & 0,23 & 0,24 & 0,25 \\
\hline & 50 & 0,22 & 0,24 & 0,21 & 0,22 \\
\hline \multirow{4}{*}{8} & 25 & 0,16 & 0,18 & 0,15 & 0,13 \\
\hline & 30 & 0,18 & 0,18 & 0,13 & 0,19 \\
\hline & 40 & 0,15 & 0,17 & 0,13 & 0,13 \\
\hline & 50 & 0,15 & 0,16 & 0,13 & 0,12 \\
\hline \multirow{4}{*}{10} & 25 & 0,19 & 0,19 & 0,12 & 0,13 \\
\hline & 30 & 0,18 & 0,18 & 0,12 & 0,14 \\
\hline & 40 & 0,17 & 0,16 & 0,13 & 0,13 \\
\hline & 50 & 0,16 & 0,16 & 0,12 & 0,12 \\
\hline
\end{tabular}

Os resultados mostram que os teores de 8 e 10\%, independente do cobrimento e do fator água/aglomerante, apresentam baixo risco de corrosão (leituras mais positivas que $-0,20 \mathrm{~V}$ ) nas condições testadas. Contudo, a análise das amostras do concreto referência e com teor de $4 \%$, em ambas relações a/ag, com exceção do cobrimento de $5 \mathrm{~cm}$, apresentaram leituras incertas, ou seja, pode ou não haver corrosão naquele momento e região estudados. Os resultados obtidos neste procedimento são favoráveis ao ensaio de índice de vazios, dado que os grupos com maior teor de vazios, isto é, o concreto referência e com $4 \%$ de sílica ativa, apresentaram resultados menos satisfatórios em comparação aos demais. 


\section{CONCLUSÃO}

Os resultados obtidos mostram que, em ambiente propício, a adição de sílica ativa, independente da relação água/aglomerante, proporciona maiores resistências às amostras de concreto em comparação ao concreto referência. O fenômeno deriva das reações pozolânicas entre a sílica ativa e o hidróxido de cálcio, que reduzem a zona de transição, considerada elo fraco do sistema. Associado a esse fato, há o efeito microfíler, um maior empacotamento das partículas em razão das dimensões microscópicas do resíduo industrial, que se torna mais evidente a partir de sua utilização síncrona com aditivos redutores de água, devido a sua ação defloculante sobre as partículas de cimento.

Contudo, a exposição à ação de cloreto de sódio mostrou que a simples utilização da sílica ativa no concreto não aprimora seu desempenho frente à agressividade do meio, tornando-se necessária a utilização de teores mínimos. Nesse estudo, os teores de sílica ativa que apresentaram melhor eficácia foram de 8 e $10 \%$, para a relações a/ag de 0,40 e 0,50. Sob uma perspectiva ecônomica, o teor de $8 \%$ apresentou melhores resultados. É possível observar ainda a possibilidade de utilização da relação água/aglomerante de 0,50 para uma condição de agressividade apresentada pela água do mar, valor superior ao apresentado na NBR 6118:2014, quando utilizado concreto com sílica ativa, ao notar-se que a resistência à compressão atingiu valores superiores a $40 \mathrm{MPa}$, valor mínimo recomendado pela NBR 12655:2015.

Ademais, os vazios foram constatados como fator primordial para o desempenho do concreto, visto que as maiores quedas de resistência ocorreram nas amostras com maior índice de vazios, influenciando também significativamente na análise do potencial de corrosão, posto que os concretos com menores índices de vazios de cada relação água/aglomerante apresentaram resultados de probabilidade de corrosão mais satisfatórios.

\section{REFERÊNCIAS}

AMERICAN SOCIETY FOR TESTING AND MATERIALS. ASTM G1-03: Standard practice for preparing, cleaning and evaluating corrosion test specimens. In: Annual Book of ASTM Standards. Philadelphia, 2011.

AMERICAN SOCIETY FOR TESTING AND MATERIALS. ASTM C876-09: Standard method for half cell potential of uncoated reinforcing steel in concrete. In: Annual Book of ASTM Standards. Philadelphia, 2009.

ASSOCIAÇÃO BRASILEIRA DE NORMAS TÉCNICAS. NBR 5739: Concreto - Ensaios de compressão de corposde-prova cilíndricos. Rio de Janeiro: ABNT, 2015.

ASSOCIAÇÃO BRASILEIRA DE NORMAS TÉCNICAS. NBR 6118: Projeto de estruturas de concreto Procedimento. Rio de Janeiro: ABNT, 2014.

ASSOCIAÇÃO BRASILEIRA DE NORMAS TÉCNICAS. NBR 7211: Agregados para concreto - Especificação. Rio de Janeiro: ABNT, 2009.

ASSOCIAÇÃO BRASILEIRA DE NORMAS TÉCNICAS. NBR 9778 Versão Corrigida de 2009: Argamassa e concreto endurecidos - Determinação da absorção de água, índice de vazios e massa específica. Rio de Janeiro: ABNT, 2005.

ASSOCIAÇÃO BRASILEIRA DE NORMAS TÉCNICAS. NBR 12655: Concreto de cimento Portland - Preparo, controle, recebimento e aceitação - Procedimento. Rio de Janeiro, 2015.

ASSOCIAÇÃO BRASILEIRA DE NORMAS TÉCNICAS. NBR 16605: Cimento Portland e outros materiais em pó Determinação da massa específica. Rio de Janeiro: ABNT, 2017.

ASSOCIAÇÃO BRASILEIRA DE NORMAS TÉCNICAS. NM 45: Agregados - Determinação da massa unitária e do volume de vazios. Rio de Janeiro: ABNT, 2006.

ASSOCIAÇÃO BRASILEIRA DE NORMAS TÉCNICAS. NM 52: Agregado miúdo - Determinação da massa específica e massa específica aparente. Rio de Janeiro: ABNT, 2009.

ASSOCIAÇÃO BRASILEIRA DE NORMAS TÉCNICAS. NM 53: Agregado graúdo - Determinação da massa específica, massa específica aparente e absorção de água. Rio de Janeiro: ABNT, 2009. 
ASSOCIAÇÃO BRASILEIRA DE NORMAS TÉCNICAS. NM 248: Agregados - Determinação da composição granulométrica. Rio de Janeiro: ABNT, 2003.

GJØRV, Odd E. Projeto da durabilidade de estruturas de concreto em ambientes de severa agressividade. $1^{\text {a }}$ ed. São Paulo: Oficina de Textos, 2015.

KOSMATKA, Steven H.; KERKHOFF, Beatrix; PANARESE, William C.; Design and control of concrete mixtures.

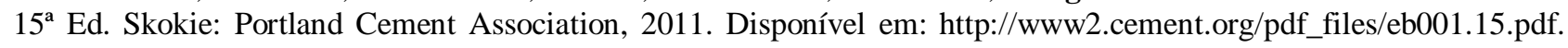
Acesso em: 01 mai. 2019.

LIMA, Raquell da Silva. Efeito do ciclo de molhagem e secagem na resistividade elétrica superficial e na resistência à compressão do concreto: simulação da agressividade marinha. 2017. 115 p. Monografia (Graduação em Engenharia Civil), Universidade Federal do Paraná. Curitiba, 2017. Disponível em: http://www.dcc.ufpr.br/mediawiki/images/6/6c/TCC_Raquell.pdf. Acesso em 23 jul. 2018.

MEHTA, P. K.; MONTEIRO, P. J. M. Concreto: microestrutura, propriedades e materiais. $3^{\text {a }}$ ed. São Paulo: IBRACON, 2008.

NEVILLE, A. M. Propriedades do concreto. 5. ed. Porto Alegre: Bookman, 2016.

SANTOS, Vito Assis Alencar dos. Avaliação da durabilidade do concreto utilizado em postes em São Luís. 2016. 178 p. Tese (Doutorado em Engenharia Civil), Universidade Federal de São Carlos. São Carlos, 2016. Disponível em: https://repositorio.ufscar.br/bitstream/handle/ufscar/8438/TeseVAAS.pdf. Acesso em 08 ago. 2018.

SILICA FUME ASSOCIATION. Silica fume user's manual. Lovettsville, 2005. E-book. Disponível em: http://www2.cement.org/pdf_files/eb001.15.pdf. Acesso em: 04 out. 2018.

SUGAMOSTO, Jorge. Comparativo entre concretos produzidos com sílica ativa em pó e sílica ativa em forma de lama. 2007. 43 f. Monografia (Graduação em Engenharia Civil), Universidade Tecnológica Federal do Paraná. Curitiba, 2007. Disponível em: https://www.tecnosilbr.com.br/wp-content/uploads/2018/05/Comparativo-de-silicaTCC_UTFPR_2007.pdf. Acesso em 22 nov. 2018.

TUTIKIAN, B.; ISAIA, Geraldo C.; HELENE, Paulo. Concreto de alto e ultra-alto desempenho. In: Geraldo C. Isaia. (Org.). Concreto: Ciência e Tecnologia. 1 ed. São Paulo: Ibracon, 2011, v. 2, p. 1283-1325. 